\section{Expedições alemães que fundaram a etnologia da Amazônia}

\section{Por Sebastian Drude}

Doutor em Linguística pela Freie Universität Berlin. Dilthey-Fellow da Goethe-Universität Frankfurt e Pesquisador Associado do Museu Paraense Emílio Goeldi/MCT (sebastian.drude@gmail.com)

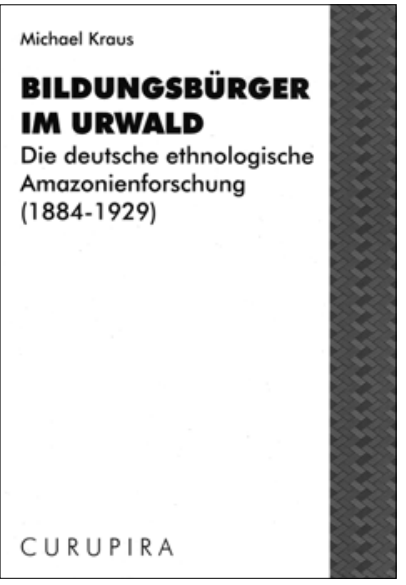

KRAUS, Michael. Bildungsbürger im Urwald: Die deutsche ethnologische Amazonienforschung (1884-1929) Marburg: Curupira, 2004. 539 p.: il. ISBN 3-81850397-4.

Existem hoje, no Brasil, várias instituições, especialmente universidades e museus, onde se realizam pesquisas científicas dedicadas à população nativa, suas culturas e línguas, em particular na Amazônia. É impossível se interessar por esta área de estudos sem conhecer bem os nomes de seus fundadores, entre eles muitos alemães, como Karl von den Steinen, Theodor Koch-Grünberg e outros. Mas quem eram esses ilustres personagens? Cientistas eruditos? Aventureiros? O que fizeram aqui, como se organizavam, como obtinham financiamento, como aproveitaram suas viagens? $\bigcirc$ que os motivou? Quais eram os principais conhecimentos buscados e obtidos por suas pesquisas? E por que a tradição etnológica alemã, que tanto prometia no século XIX, foi praticamente interrompida nos anos 1920 ?
Com esta obra, cujo título em português poderia ser "Burgueses de educação (ou de formação) na selva: a pesquisa etnológica alemã na Amazônia (1884-1929)", o antropólogo alemão Michael Kraus ${ }^{1}$ apresenta um estudo completo e detalhado com algumas respostas para estas perguntas. Esta obra preenche uma lacuna, pois além de algumas notas bio- e bibliográficas (em especial as feitas no Brasil por Herbert Baldus e Egon Schaden), não há muito material disponível sobre os fundadores dos estudos científicos antropológicos e linguísticos sobre a população indígena das terras baixas da América do Sul ${ }^{2}$. No entanto, mesmo que hoje não seja um fato amplamente conhecido, esta área de estudos foi uma das mais destacadas no estabelecimento da disciplina 'etnologia/antropologia'.

O estudo de Kraus tem quase 500 páginas, além de 35 páginas de referências. Estas proporções são indício de uma das características mais notáveis do livro: um grande cuidado e respeito pelas fontes originais e pelos seus autores. Apesar deste rigor científico exemplar (em média, três notas de rodapé por página, muitas com valiosas observações adicionais), o livro em nenhum momento é uma leitura seca ou chata - ao contrário, é muito bem escrito (a linguagem chega a ter qualidades literárias) e prende o leitor em todas as páginas.

O foco do trabalho são as viagens ou expedições dos pesquisadores alemães; as condições institucionais e pessoais constituem seu fundo; os resultados científicos são abordados de forma sucinta. O livro é estruturado em cinco partes, iniciadas por um curto prólogo que explica a ênfase e a abordagem escolhidas. A segunda parte, "condições básicas na Alemanha", tem três capítulos: um apresenta os pesquisadores examinados; o seguinte, as instituições envolvidas; enquanto que o último analisa as motivações individuais e institucionais, a concorrência e o papel da

1 alemão Michael Kraus, que obteve seu doutoramento em 2002 em Marburg com uma tese que depois transformou neste livro, não deve ser confundido com Michael E. Krauss, linguista norte-americano baseado em Fairbanks, Alaska, que estuda as línguas nativas norte-americanas, nem com os desportistas alemães homônimos.

2 No Brasil, felizmente, existe o tomo editado por Vera Penteado Coelho (1993), embora este seja limitado aos estudos do Alto Xingu e, em particular, aos de Karl von den Steinen.

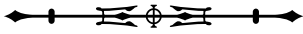


então jovem disciplina 'etnologia', ainda em processo de constituição, discutindo, por exemplo, sua fixação em objetos etnográficos.

Os pesquisadores examinados são Karl von den Steinen, Paul Ehrenreich, Konrad T. Preuss, Theodor KochGrünberg, Max Schmidt e Fritz Krause (ao final do livro, o leitor parece conhecer estes pesquisadores como se tivesse convivido algum tempo com eles). São incluídos, ainda, mas com menos ênfase, três pesquisadores que não foram amazonistas ou que não foram cientistas profissionais: Hermann Meyer, Wilhelm Kissenberth e Felix Speiser.

A parte principal do trabalho, "expedições à Amazônia", consiste de três capítulos extensos dedicados a três 'passos' das expedições: 1) os preparativos e a viagem até a América do Sul; 2) as viagens até a região dos índios; e 3) as pesquisas em si, no local de destino. Para cada etapa, Kraus organiza sua exposição em três ou quatro subcapítulos temáticos. Por exemplo, o sub-capítulo III.2.4, "Trabalhadores braçais de mula, lenha e remo: - Os 'camaradas' da ciência”, consiste de 25 páginas dedicadas às relações de cooperação, amizade, conflito, dependência e poder entre os pesquisadores e seus acompanhantes europeus, crioulos e indígenas. Analisa desde a quantidade de pessoas envolvidas (ao longo do tempo, as expedições levavam cada vez menos acompanhantes, o que ajudava a intensificar o contato direto entre os pesquisadores e a população nativa estudada, indicando que o ideal moderno da pesquisa de campo como experiência de imersão cultural já existia na época) até as personalidades e os estilos dos pesquisadores ao lidar com este aspecto das expedições. Para cada um destes aspectos, Kraus apresenta o que encontrou no rico material deixado pelos pesquisadores e, ao comparar diferentes expedições e relatos, identifica padrões e características individuais dos cientistas e de suas pesquisas. A maioria dos subcapítulos são estudos preciosos, que podem ser considerados separadamente, sem perder seus méritos.

A parte quatro, "a antropologia dos etnógrafos", dirige seu foco sobre a história da ciência, analisando as ideias, a visão e as contribuições dos pesquisadores, sem, contudo, apresentar análise e avaliação abrangentes de seus resultados etnográficos e antropológicos, a partir das teorias e dos conhecimentos atuais. Em vez disso, os dois capítulos elucidativos desta parte, "metodologia e temática" e "teoria e visão global", tentam se aproximar do native's point of view - ou seja, da visão e concepção dos próprios pesquisadores estudados.

Isto, aliás, é um dos pontos mais marcantes do livro. Kraus sempre procura se aproximar dos pesquisadores que estuda como um etnógrafo deve se aproximar de uma população nativa - procurando um entendimento profundo e holístico, ciente das próprias limitações e do fato de não estar livre das influências de sua própria origem e formação, respeitando a visão 'êmica' em vez de julgá-los etnocentricamente ou, neste caso, 'cronocentricamente'. Evidentemente, esta abordagem encontra seus limites nas fontes existentes - não foi possível para Kraus entrevistar os pesquisadores estudados e muito menos participar como observador das suas pesquisas (é interessante ver como os alemães eram, em geral, francos e honestos o bastante para admitir suas próprias limitações e falhas - 0 que contrasta com a visão muitas vezes difundida sobre eles, de acordo com a qual estes buscariam esconder os lados menos bem sucedidos de suas pesquisas, na suposta tentativa de construir uma imagem impecável).

O procedimento escolhido por Kraus tem o mérito de ser muito mais instrutivo do que a simples confirmação (ou não) das opiniões modernas difundidas sobre a etnologia do final do século XIX. Assim, um ponto que Kraus discute em várias passagens do livro é que, muitas vezes, o discurso moderno e supostamente 'desmistificador' sobre os fundadores da disciplina é, de fato, preconceituoso e algo arrogante, não conseguindo fazer jus à obra realizada e ao avanço científico que esta trouxe. Isto vale, em particular, para o discurso pósmoderno e desconstrutivista - em muitas ocasiões, em contraste com os nossos preconceitos, é possível perceber que os pesquisadores antigos tinham uma visão muito mais 
diferenciada dos 'índios' e de suas culturas do que a que seus críticos modernos têm destes pesquisadores.

Felizmente, Kraus raramente corre o risco de idealizar os pesquisadores alemães, e tampouco fecha os olhos diante de ideias ou comportamentos que são inaceitáveis, do atual ponto de vista (e, às vezes, também a partir de um ponto de vista humanista já existente na época). Em geral, os pesquisadores estudados surgem como humanistas e críticos do etnocentrismo e das crenças progressistas de sua época; e como pensadores independentes e, em vários aspectos, céticos das teorias universalistas (em particular, do evolucionismo e do difusionismo). Depois da Primeira Guerra Mundial, chegaram a ser pessimistas sobre a própria cultura ao compararem-na com as culturas indígenas por eles observadas. Este contraste entre 'nossa' cultura e as dos povos indígenas já era bastante visível nas próprias viagens, no contexto colonial e de exploração do interior da Amazônia, em particular durante o primeiro ciclo da borracha, que marca a época das viagens estudadas por Kraus. As pesquisas não deixaram de se realizar neste contexto violento, que, às vezes, era vantajoso para elas, outras vezes não. Isso não significa que as pesquisas fossem de motivação ou caráter colonialista ou explorador, como tantas vezes se proclama. Como Kraus mostra convincentemente, ao menos entre os pesquisadores interessados na Amazônia, a tradição humanista e liberal se manteve viva nos anos 1920. Os homens aqui abordados estavam muito mais preocupados em contribuir para a construção de conhecimento, universal sobre a diversidade cultural ainda existente, do que com interesses nacionais e imperialistas, econômicos ou missionários ${ }^{3}$.

Lamentavelmente, preconceitos contra pesquisadores do 'primeiro mundo' retornam, hoje, por exemplo, sob o rótulo de 'combate à biopirataria', no discurso nacionalista e também no discurso anti-imperialista e anti-globalização, supostamente progressista, colocando sob suspeita todo tipo de cooperação internacional. Este não é o único paralelo à situação atual que se pode estabelecer ao ler a obra de Kraus. Quem já fez expedições para estudar grupos indígenas pode ver as próprias experiências espelhadas nos relatos dos viajantes de 100 ou 120 anos atrás, por exemplo, quando são abordados problemas de financiamento ou de transporte, o ritmo diferente do tempo na viagem e 'no campo', e, em particular, os relacionamentos (sempre muito diversos e heterogêneos) com indivíduos e grupos indígenas. Estas relações são descritas muito vivamente pelos pesquisadores e Kraus consegue transmitir esta plasticidade em seu trabalho.

Prosseguindo na comparação da situação da época com a de hoje: embora a população indígena tenha se mostrado, em geral, bem mais resistente do que se poderia imaginar a partir dos cenários pessimistas de alguns dos ilustres cientistas de um século atrás, a situação geral das populações amazônicas, inclusive no Brasil, não é muito animadora, pois continua a ser marcada pela dominação, pela ignorância, pelo desrespeito, pela negligência e, às vezes, pela violência brutal. Na época, como hoje, qualquer pesquisa que ignora esta realidade está condenada a ser julgada de forma negativa pela posteridade. Muito se perdeu nos últimos 100 anos. Assim, os relatos dos pesquisadores são, muitas vezes, as únicas fontes de informação sobre elementos culturais ou sobre grupos indígenas que não existem mais. Como o processo da globalização (interno e externo) está se acelerando cada vez mais, o risco de perder muito mais nos próximos 100 anos é iminente. Na época, como hoje, somente uma parcela pequena da sociedade está ciente destas questões, e muitas vezes não é fácil achar aliados e apoio substancial nas instituições estatais na tentativa de documentar e preservar a riqueza cultural e linguística ainda existente, tarefa cada dia mais urgente ${ }^{4}$.

3 Nisto, Kraus confirma os resultados de Penny (2002), que salientam a visão humanista, anti-racista e o interesse pelo entendimento holístico, do ponto de vista êmico, das culturas humanas (no plural, já nos anos 1880), dominantes na etnologia na Alemanha entre 1870 e 1920.

4 Recentes iniciativas da Fundação Nacional do Índio (FUNAI), como os projetos de documentação de línguas e culturas indígenas do Museu do Índio, são motivo para alguma esperança neste contexto. Ver http://prodoc.museudoindio.gov.br/.

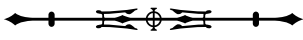


Também neste sentido, há boas razões para crer que é lamentável que a tradição alemã da etnologia dos grupos indígenas que habitam as terras baixas da América do Sul não tenha conseguido se recuperar da ruptura que significou a Primeira Guerra Mundial. É deplorável que esta área de estudos não tenha conseguido estabelecer-se nas universidades alemãs (até hoje, na Alemanha, pouquíssimas cadeiras de Etnologia possuem professores com esta especialidade), sendo, posteriormente, quase esquecida nesse país, muito embora em outros, inclusive nos Estados Unidos ${ }^{5}$ e no Brasil, suas contribuições sejam valorizadas até hoje. No seu epílogo, Kraus reflete brevemente sobre os caminhos desta área de estudos na Alemanha depois da época delimitada pelo seu trabalho (de 1884 a 1929 , anos da primeira expedição ao Xingu e da morte de Karl von den Steinen, respectivamente).

A única crítica que se poderia fazer às 500 páginas do livro de Kraus é a mesma que J. R. R. Tolkien acatou em relação ao seu "Senhor dos Anéis": "O livro é curto demais". Porém, era necessário, embora lamentável, que o livro se restringisse para poder ser finalizado e publicado. Seria muito bom podermos dispor de uma abordagem semelhante para os precursores (em particular, von Martius) e para alguns estudiosos que não faziam parte da comunidade científica alemã, não tendo sido, por isso, incluídos neste estudo. $\bigcirc$ próprio autor admite que, provavelmente, muitos iriam sentir falta de Curt Nimuendajú na lista dos estudados. Uma das maiores lacunas na historiografia da antropologia brasileira é a ausência de estudos detalhados sobre as viagens deste pesquisador e sobre os resultados que obteve, e a não publicação da sua volumosa obra inédita ${ }^{6}$ (o mesmo vale para outros pesquisadores, ainda falando de alemães, como Emilie e Emil Snethlage).

Em suma, o estudo de Michael Kraus é de grande valor e merece ser conhecido internacionalmente, sobretudo entre os antropólogos no Brasil. Por sorte, várias das obras dos ilustres alemães vêm sendo traduzidas e continuam nas listas de leitura dos cursos universitários. É desejável que o mesmo aconteça com o livro de Kraus.

\section{AGRADECIMENTO}

Agradeço a Miriam Junghans por valiosos comentários a uma versão anterior desta resenha.

\section{REFERÊNCIAS}

BUNZL, Matti. Franz Boas and the humboldtian tradition: from Volksgeist and Nationalcharakter to an anthropological concept of culture. In: STOCKING JR., G. W. (Org.). Volksgeist as Method and Ethic. Madison: University of Wisconsin Press, 1996. p. 17-78.

COELHO, Vera Penteado (Org.). Karl von den Steinen: um século de antropologia no Xingu. São Paulo: EDUSP, 1993.

DUNGS, Günther F. Die Feldforschung von Curt Unckel Nimuendaju und ihre theoretisch-methodischen Grundlagen. Bonn: Holos, 1991. (Série Mundus Ethnologie, v. 43).

FRANK, Erwin. "Viajar é preciso": Theodor Koch-Grünberg e a Völkerkunde alemã do século XIX. Revista de Antropologia, v. 48, n. 2, p. 559-584, 2005.

PENNY, H. Glenn. Objects of Culture: Ethnology and Ethnographic Museums in Imperial Germany. Chapel Hill: University of North Carolina Press, 2002.

\footnotetext{
5 Neste contexto, vale lembrar que Franz Boas recebeu uma parte importante de sua formação nos museus etnológicos alemães. Suas ideias anti-etnocentristas, que hoje são um dos pilares da antropologia moderna, mostram que ele, como também os pesquisadores aqui em foco, era parte da mesma tradição humanista pluri-culturalista alemã, iniciada por Herder e continuada por Wilhelm Humboldt e Adolf Bastian (Bunzl, 1996; Frank, 2005).

6 Existem poucos estudos em alemão sobre este pesquisador, notadamente Dungs (1991), que também merecem ser conhecidos no Brasil.
}

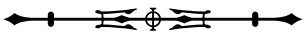

